\title{
Who Talks and Who Listens? How Political Involvement Influences the Potential for Democratic Deliberation in Everyday Political Talk
}

\author{
Lea Gärtner, Alexander Wuttke and Harald Schoen
}

In times of rising partisan polarization and increasing disenchantment with political elites, everyday political talk could constitute an important venue for citizen deliberation. Everyday political discussions offer ordinary people opportunities to strengthen deliberative skills, form considered preferences, and hone political identities in relation to others. However, informal political discussions seldom follow the norms of formal deliberative fora, calling into question how often such everyday talk really enables democratic deliberation in the broader public. The answer is essential to assess the deliberative potential of everyday political talk and thus to understand its role in the deliberative system. Focusing on the democratic and deliberative standards of reason-giving, mutual respect, equality, and inclusion, we develop a multistep model of democratic deliberation in everyday political talk, in which the potential for democratic deliberation depends on the presence of all four core standards. As individuals' propensity for democratic deliberation is likely to vary with their level of political involvement, both in terms of how much they care about politics and how strongly they identify with political groups, we consider both dimensions when modeling democratic deliberation in individuals' everyday political discussions. We test all steps of the model with data from a large panel survey tracing the informal political discussion networks of 18,079 German voters during the year leading up to the national elections in 2017. Our findings indicate that everyday political talk is more deliberative than expected, as the three core standards of democratic deliberation we can measure are largely upheld in people's political exchanges.

Keywords: everyday political talk; political involvement; political discussion networks; democratic deliberation; panel data

\begin{abstract}
Introduction
In times of rising partisan polarization and increasing disenchantment with political elites, democratic deliberation promises to bridge some of the divides between different societal groups, strengthen the understanding of competing interests, and engage ordinary people in political decision-making (Knobloch, 2011; Knobloch \& Gastil, 2014). Evidence from deliberative fora such as mini-publics confirms that, in the right setting, people are surprisingly capable of democratic deliberation (e.g., Gerber et al., 2018; Warren \& Pearse, 2008). However, the opportunity for democratic deliberation among ordinary people arises much more frequently in informal political discussions with friends and acquaintances than in the controlled environment provided in deliberative fora (Habermas, 2006; Mansbridge, 1999). Hence, political discussions between ordinary people could be powerful
\end{abstract}

Chair for Political Science, Political Psychology, University of Mannheim, Mannheim, DE

Corresponding author: Lea Gärtner

(lea.gaertner@uni-mannheim.de) sites for strengthening citizens' deliberative skills (cf. Eveland Jr. et al., 2011; Gutmann \& Thompson, 1999, 2004), enabling them to form considered preferences and hone their political identity in relation to others (Neblo, 2015; Pincock, 2012), even encouraging political participation, tolerance and civic-mindedness (cf. Conover \& Miller, 2018; Gastil et al., 2008, 2010). Yet, not all political talk elicits reasoned opinions and deliberative practice. Political discussions that violate democratic and deliberative standards may even have negative effects, for instance when echo chambers inhibit tolerance for other opinions. Considering that most everyday political exchanges are an incidental side product of people's desire to enter and sustain meaningful social relationships (Conover \& Searing, 2005), how often do informal political discussions really enable democratic deliberation in the broader public? The answer to this question is essential to understand the function of everyday political talk in the deliberative system and to assess its deliberative potential. We add to prior studies examining the democratic and deliberative quality of people's everyday political discussions by analyzing data from a large panel survey, 
which traces respondents' political discussion networks outside of controlled environments such as mini-publics and focus groups.

In keeping with recent efforts to sharpen the concept of democratic deliberation (e.g., Bächtiger \& Parkinson, 2019), we focus on four core standards that are included in almost all definitions of democratic deliberation: reason-giving, mutual respect, equality, and the inclusion of different perspectives (e.g., Bächtiger et al., 2018; Bächtiger \& Parkinson, 2019; Conover et al., 2002; Habermas, 2006). So far, studies assessing the deliberative potential of people's everyday political discussions have focused on compliance with individual standards of democratic deliberation (cf. Conover \& Miller, 2018; for an exception see Conover et al., 2002). However, thinking about how these standards are met in everyday political talk, it would seem that democratic deliberation emerges from their concurrence rather than full compliance with any one standard. People can explain the reasons behind their positions without respecting the opinions of others, or respectfully consider the arguments made in an exclusive circle of like-minded discussants, but neither situation would further the goals associated with democratic deliberation (Bächtiger \& Parkinson, 2019, pp. $28 \mathrm{ff}$.). Finding the best possible solution, generating mutual respect, learning about novel arguments, and understanding other perspectives all require that people with different perspectives come together and listen to each other. At least finding the best possible solution and understanding competing perspectives also require that no societal group is excluded from deliberating (Polletta $\&$ Gardner, 2018). Therefore, we conceptualize democratic deliberation in informal political discussions as a multistep process, in which the potential for democratic deliberation depends on the presence of all four core standards. By extending the examination of single necessary but insufficient standards, we hope to obtain a more accurate assessment of the potential for democratic deliberation in the broader public.

From the literature on political participation, we know that political involvement greatly influences how much and in which ways individuals participate in politics. We suspect that this is also true for people's potential to participate in democratic deliberation, and that people's political involvement, both in terms of how much they care about politics (domain-related involvement) and how strongly they identify with political groups (grouprelated involvement) influences whether the standards of democratic deliberation are met in their everyday political discussions. For example, the trend towards political disengagement (e.g., Dassonneville et al., 2012; Goodliffe, 2012; Mounk, 2018) may be concerning for the standards of equal participation and inclusion of different perspectives because political disengagement is concentrated among the socially disadvantaged (Armingeon \& Schädel, 2015; Gallego, 2007), effectively turning deliberation into another, and not necessarily democratic, source of political influence for highly involved activists. Similarly, considering that polarization fosters homophily (e.g., Sunstein, 2017) and motivated reasoning (Taber \& Lodge,
2006), citizens' increasing division along partisan lines (e.g., Iyengar et al., 2019; Mounk, 2018; Reiljan, 2019) could diminish their willingness to expose themselves to, not to mention give fair consideration to, diverse opinions. Hence, political involvement is likely to influence each standard of democratic deliberation differently, and different dimensions of political involvement may even affect the same standard in different ways. Therefore, we differentiate between group- and domain-related involvement when assessing the overall influence of political involvement on the potential for democratic deliberation in everyday political encounters.

To test the potential for democratic deliberation in everyday political discussions, we draw on information on the political discussion networks of 18,079 German voters, reported in the year leading up to the national elections in 2017. Our findings indicate that everyday political talk is more deliberative than expected, as the three core standards of democratic deliberation we can measure are largely upheld in citizens' political exchanges.

\section{Theory and Hypotheses}

Because informal political discussions between ordinary people offer the most prevalent opportunity for democratic deliberation, assessing how often everyday political discussions really enable democratic deliberation is essential to understand the role of informal political talk in the deliberative system and its potential to elicit the positive effects demonstrated in more controlled deliberative environments such as mini-publics in a broader public. In exploring the potential for democratic deliberation in everyday political talk, we focus on four standards that are at the core of democratic deliberation: reason-giving, mutual respect, equality, and the inclusion of different perspectives (e.g., Bächtiger et al., 2018; Bächtiger \& Parkinson, 2019; Conover et al., 2002; Habermas, 2006).

Reason-giving requires that, in addition to stating their opinions, people reveal the considerations that motivate their stances (Habermas, 1990; Mansbridge, 1999, 2015). Most contemporary deliberation scholars agree that such relevant considerations do not need to involve rational argumentation but may instead be based on emotions and personal experiences (see Bächtiger et al., 2018 for a more detailed discussion). Mutual respect demands that people actively listen to their discussion partners and make an effort to understand their perspectives, instead of discounting them without fair consideration (Dryzek, 2000; Gutmann \& Thompson, 1996, 2014, 2018). Equality refers to an equal opportunity to participate in and influence deliberation, requiring that nobody is excluded from political discussions (Habermas, 2008; Knight \& Johnson, 1997). We follow Conover, Searing \& Crewe in interpreting equality in everyday political discussions as "a demand that disadvantaged groups not be excluded systematically from [informal] discussions" (2002, p. 41). Inclusion speaks to both equality and the absence of power in stipulating that democratic deliberation must admit different viewpoints and reasons must remain open to contestation (Bohman, 1996). 
Every one of the core standards engenders an essential component of democratic deliberation, yet none is sufficient on its own to further goals such as finding solutions that everybody can identify with, learning about novel and competing arguments, and fostering mutual respect and understanding. In consequence, most deliberation theorists agree that the emergence of democratic deliberation is inextricably linked to the concurrence of these essential components rather than full compliance with any one standard (e.g., Bächtiger \& Parkinson, 2019; Morrell, 2018; Steenbergen et al., 2003). In practice, everyday political discussions must meet all four standards to attain the goals of democratic deliberation, implying a multi-step process in which the potential for democratic deliberation depends on the presence of all core standards and which may fail at any one step. People can actively listen to arguments supporting their own opinion, made in an exclusive circle of advantaged discussants, but most deliberation theorists would not label such a discussion deliberative or democratic. As long as disadvantaged groups are excluded from the discussion, people can even actively listen to a range of other perspectives, yet this discussion would still not be democratic and most likely not deliberative.

The first step towards democratic deliberation is thus that people, especially people that tend to be marginalized, have an equal opportunity to participate in political discussions. In the next step, equality has to be translated into inclusivity, that is people must actually admit different and competing viewpoints in their personal discussion networks. Neither equality nor inclusivity are meaningful to attain the goals of democratic deliberation if people do not listen to each other and fairly consider other viewpoints. Hence, the third step towards democratic deliberation is mutual respect. Lastly, none of these steps would further the goals of democratic deliberation if people did not explain their opinions, making reason-giving the final condition for democratic deliberation in everyday political talk. Figure 1 illustrates our multi-step model, which integrates the four democratic and deliberative core standards to capture the potential for democratic deliberation in the broader public. Unfortunately, we cannot measure reason-giving and therefore the following discussion focuses on equality, the inclusion of different perspectives, and mutual respect.

Compared to previous studies, our multi-step understanding of democratic deliberation is more comprehensive and therefore sets a high bar against which informal political discussions are measured. Meeting these conditions may be especially difficult in times when increasing numbers of citizens retrench into partisan camps or withdraw from the political domain altogether (e.g., Goodliffe, 2012; Mounk, 2018; Reiljan, 2019). The former development is an expression of increasing group-related political involvement, that is an increasing attachment to political groups, most often political parties (Dalton, 2007; Klein, 2020). The latter is the result of waning domainrelated involvement, that is decreasing engagement with all things political, as visible in, for instance, decreasing political interest (e.g., Foa \& Mounk, 2017).

Even though the two dimensions of political involvement often coincide in reality, their effects on democratic deliberation are distinct and may even contradict each other. For instance, higher domain-related involvement may encourage people to expose themselves to a range of perspectives, whereas higher group-related involvement is more likely to motivate citizens to avoid other perspectives (e.g., Brannon et al., 2007; Huckfeldt \& Sprague, 1995). Hence, testing these dimensions in separate models or combining them in one indicator (e.g., Dalton, 2007, 2012; Huddy \& Khatib, 2007; Prior, 2007) is likely to confound the different and sometimes adverse effects of these two dimensions of political involvement. Because more involvement does not necessarily equal better chances for democratic deliberation, we need to consider how each dimension of political involvement affects each of the four core standards to reliably assess the overall impact of political involvement on the potential for democratic deliberation in everyday political talk.

We expect domain-related involvement to exert a positive influence on participation in political talk and the willingness to include dissonant views in political discussions, but have contradicting hypotheses regarding its impact on active listening and the fair consideration of other opinions. Individuals who are highly involved in the political domain are those who care about politics and derive inherent pleasure from engaging with political information (e.g., Prior, 2019; Wuttke, 2021). Because the political domain is constantly changing, people who find it important to be informed about political affairs will have a continued need to observe and discuss political events. In addition, for highly domain-involved individuals who find pleasure in political engagement, political conversation may also be an end in itself, much

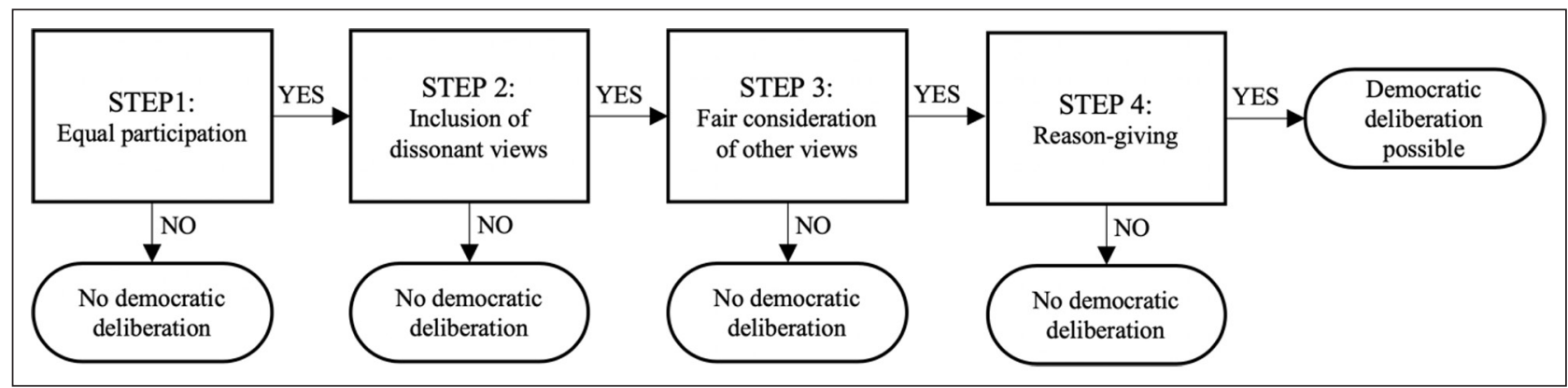

Figure 1: Multi-step model of high-quality deliberation in everyday political talk. 
like any other enthusiast enjoys talking about their object of affection (Prior, 2019). Consequently, highly domaininvolved people have psychological incentives to discuss politics more often and with more discussion partners than people who are less involved in the political domain.

Considering their propensity to actively seek information enabling them to improve their knowledge and potentially update their beliefs on the political domain, highly domain-involved people should also be more inclined than their less domain-involved counterparts to expose themselves to different viewpoints and thus to seek cross-cutting discussions (e.g., Dubois \& Blank, 2018). Moreover, prior research has shown that low domain-related involvement engenders an aversion to ambiguity, paired with the inclination to maintain clearcut world views (Rinke \& Moy, 2016). Because discussion partners with different viewpoints make for a more diverse but also more ambiguous information source, we expect that highly domain-involved individuals will strive to create heterogeneous political discussion networks, whereas people who are less involved in the political domain should avoid exposure to dissonant views.

At first glance, it seems clear that their inherent motivation to improve their understanding of the political domain should also enhance the likelihood that highly domain-involved people will actively listen to and fairly consider other viewpoints. Individuals with low levels of domain-related involvement, on the other hand, may simply ignore information about politics, as they do not experience engagement with the political domain as rewarding. However, exactly because highly domaininvolved individuals are likely to have extensive knowledge of the political domain, they are also likely to possess crystallized political attitudes. Hence, highly domaininvolved individuals may consider it superfluous to carefully listen to others, who presumably know less about politics than themselves. In the same vein, less involved individuals may feel less certain about the validity of their attitudes and thus be more willing to listen to others and consider different viewpoints (Druckman, 2012; Krosnick \& Petty, 1995). In short, there are two plausible but opposed arguments how domain-related involvement may influence active listening and fair consideration.

Regarding the impact of group-related involvement, we expect a small positive effect on participation in political discussions, but a negative influence on the willingness to expose oneself to dissonant views and the fair consideration of other opinions. Although party support is largely habitual and does not necessarily entail an increased cognitive engagement with the object of affection (Dalton, 2012), party identifiers are still likely to enjoy talking about their group identity (e.g., Iglic \& Font Fábregas, 2008; Schoen et al., 2017). Therefore, individuals with high group-related political involvement may discuss politics, much like sports fans would discuss the last game, although they lack the inherent motivation to learn about the political domain as such. Because the interest of group-involved individuals is focused around their group identity, we expect the positive effect of groupinvolvement on participation in political discussions to be considerably smaller than the impact of domain-related involvement, which implies a much broader interest in the political domain.

In contrast, group-related involvement should negatively affect exposure to dissonant views. From the extensive literature on how citizens think about politics, we know that group-related identities such as the identification with a political party are central to identifiers' belief systems and thus fiercely defended (e.g., Converse, 1964; Goren, 2005; Green et al., 2002). In consequence, strong group-related involvement prompts directional goals in the seeking and processing of information (e.g., Taber \& Lodge, 2006), leading highly group-involved people to prefer confirmatory evidence to information that contradicts prior beliefs (e.g., Barnidge, 2017; Iyengar et al., 2008). People who are strongly attached to a political group should therefore avoid information that challenges their group-related political views, including exposure to dissonant information in political discussions, and thus be less likely to admit discussion partners advocating diverse political perspectives to their political discussion networks.

Moreover, because group-involved people perceive counter-attitudinal information as challenging, they should also be less inclined to listen to and fairly consider other viewpoints. For people with a strong group identity, information challenging their group identity leads to cognitive dissonance, which is countered with motivated reasoning (Ditto \& Lopez, 1992; for a comprehensive discussion see Taber $\&$ Lodge, 2006). This psychological defense mechanism leads people to cope with dissonant information by evaluating supportive arguments as stronger and spending more cognitive resources on counter-arguing the incongruent arguments. Thus, high group-related involvement is likely to impede active listening to, not to mention the fair consideration of, dissonant views (cf. Bello \& Rolfe, 2014).

So far, we assumed that domain-related and grouprelated political involvement are the only forces shaping the composition of people's political discussion networks. We have thus neglected that people's lives seldom revolve around politics and friends and colleagues are not usually selected based solely on their political views. As we are explicitly looking at political discussion networks, it seems reasonable to assume that people are selective with regard to which friends, colleagues, or neighbors they discuss politics with, but the pool of potential discussion partners itself is unlikely to be determined solely, or even largely, by political preferences. Hence, the probability to encounter a dissonant view likely increases with the size of one's political discussion network, which is one of our indicators of participation in political talk. For our multistep model, this means that the first and second step are potentially linked by the size of people's discussion networks. To assess how political involvement influences each step separately, we thus need to distinguish between absolute levels of heterogeneity, that is the total number of discussion partners with different political positions, and relative levels of heterogeneity, that is the percentage of discussion partners with dissenting views. This is because the absolute level of heterogeneity depends on the size 
of people's discussion networks: the more discussion partners one has, the higher the probability that some of them will have different political preferences. The relative level of heterogeneity, on the other hand, takes into account the number of discussion partners and thus reflects the preferences for like-minded or differentminded discussion partners irrespective of discussion network size and hence independent of the first step. Table 1 summarizes our hypotheses for the three criteria of high-quality deliberation in everyday political talk by the dimension of involvement.

\section{Data and Methods}

We use panel survey data from the German Longitudinal Election Study (GLES) to investigate the impact of the two dimensions of political involvement on the different steps towards democratic deliberation. The GLES Campaign Panel for the German federal elections in 2017 (Roßteutscher et al., 2018) is a multi-wave longitudinal survey with seven pre-election and two post-election waves collected during the year leading up to the national elections (see Appendix 1 for collection periods and retention rates). ${ }^{1}$ It comprises longitudinal data about the political discussions and the discussion networks of a large sample of German voters and is thus uniquely fit to examine the potential for democratic deliberation in a broader public.

However, the data also comes with specific particularities and limitations that should be kept in mind when interpreting the results. First, given that turnout was higher in the 2017 federal elections than in previous years and the preceding campaign was characterized by considerable voter volatility and generated high levels of public attention (Wuttke \& Schoen, 2019), the analyzed data can be considered a most-likely case for participation in political talk. Second, while the data contains detailed information about respondents' political discussion networks, it does not report the content of their political discussions. Hence, unlike content-based measures such as the Discourse Quality Index (Steenbergen et al., 2003), which directly measure the deliberative quality of political discussions, the scope of our analyses is limited to assessing upper and lower bounds of compliance with core standards of democratic deliberation. Third, the GLES Campaign Panel 2017 draws on an online access panel and does not represent a random sample of the German population. Although respondents were recruited using socio-demographic quotas, younger respondents with lower education are underrepresented in the realized sample. In Appendix 2, we compare the distribution of central attitudinal and socio-demographic variables from the GLES Campaign Panel 2017 with equivalent data from a probability-based sample, finding only minor differences.
Despite these limitations, three features make this data particularly suitable to examine democratic deliberation in informal political discussions. First, the longitudinal nature of the data cancels out random error and enables us to examine systematic dynamics over time. Second, the survey contains a sophisticated measure of political discussion networks that could be combined with other data on the respondent. All respondents were asked to report how often they discussed politics in the past week. Respondents who had discussed politics at least once were then asked to report the initials of up to three people with whom they had discussed politics in the past week. For each of these discussants, respondents also indicated the frequency of political talk and the discussion partners' perceived vote intention. Although the discussants remain anonymous, we could uniquely identify 96 percent of the discussion partners and match them across survey waves using name initials and relationship information. ${ }^{2}$ Altogether, the name generator prompted respondents to think of real individuals in their social context and their interactions with these individuals, contributing to a high environmental validity of the measure.

Moreover, instead of querying respondents' interpretations of perceived attitudes of their conversation partners in categories such as "like-minded" or similar concepts, the discussion network instrument queries discussion partners' perceived vote intention and offers a "don't know" option in case of uncertainty. Measuring partisan rather than general disagreement (cf. Klofstad et al., 2013) has several advantages for our research design. First, the information on discussion partners' vote intentions allows us to differentiate between respondents who change their vote intentions to match their discussion partners and respondents who change their vote intention to some other party. This distinction is essential for the third step of our analysis and the interpretation of general disagreement is not straightforward in multi-party systems. Second, looking at network heterogeneity, we are more interested in whether discussion partners bring a different set of premises and arguments to the table, which seems likely if they intend to vote for a different party, than in the effects of felt disagreement. We thus capture the form of disagreement most likely to facilitate rather than impede deliberation (cf. Polletta \& Gardner, 2018).

Finally, the GLES Campaign Panel 2017 contains data on 18,079 respondents, allowing us to analyze separate subgroups to investigate whether compliance with standards of democratic deliberation varies with individual-level characteristics. Altogether, the discussion network measure allows us to examine patterns of participation in political discussion and the static heterogeneity of discussion networks, but also to trace the vote intentions

Table 1: Overview of the Hypotheses.

Equal participation Inclusion of dissonant views Fair consideration of other views

\begin{tabular}{lllc}
\hline Domain-related involvement & $\uparrow$ & $\uparrow$ & $\uparrow \downarrow$ \\
Group-related involvement & $\uparrow$ & $\downarrow$ & $\downarrow$
\end{tabular}


of respondents over time and to link these trajectories to changes in discussants' vote intentions. Thus, the data provides individual-level indicators for three of the core standards of democratic deliberation (see Appendix 2 for descriptive statistics on all variables of interest).

Our operationalization includes several measures for equal participation in political discussions. The dummy variable participation in political talk indicates whether a respondent talked about politics at all during the data collection period. Because talking about politics at all during the year before an election is a very low threshold for participation, we also consider the frequency of political talk, which indicates the number of days per week on which a respondent talked about politics on a scale from 0 to 7, and respondents' network size, which measures the average number of discussants named per wave and ranges between 0 and 3 . To assess the degree to which people admit dissonant views in their informal political discussions, we measure relative heterogeneity as the percentage of political discussion partners within the discussion network, who do not share the respondent's vote intention and absolute heterogeneity as the total number of discussion partners with dissonant vote intentions, which ranges between 0 and 3. Both measures are constructed as across-wave averages to reduce the impact of outliers. Unfortunately, we have no information about the content of the reported political discussions, which means that we cannot measure if and when people offer reasons to support their opinions and have to rely on proxy measures for active listening and respectful consideration in everyday political talk.

To capture active listening, we look at perceived changes in the vote intentions of discussion partners, which would go unnoticed unless the respondent actively processed at least some of the information exchanged in political discussions. Given that respondents could name up to three political discussion partners and their networks were queried in eight subsequent waves, any respondent could perceive a maximum of 21 opinion changes across all waves. Although opportunities to perceive changes in discussion partners' vote intent should be considerably rarer in reality because people are unlikely to change their vote choice on the fly, the 2017 electoral campaign produced considerable voter volatility and likely enhanced the attention to discussion partners' vote intentions. Our estimates could thus be considered to represent an upper border for active listening in informal political discussions.

To approximate respectful consideration, we measure the likelihood that a respondent will change her vote intention to the same party when she perceives a switch in vote intentions in her political discussion network. Given that we are interested in changes rather than crystallizing opinions, which could be considered the expected outcome of activation processes during the election campaign (e.g., Dilliplane, 2014; Schoen et al., 2017, pp. 127-144), we only look at cases in which the respondent changed her vote intention from one party to another, excluding respondents who reported a preference for the first time. All reported respondent and discussant vote intentions refer to vote intentions in the German federal election 2017 and we focus on the seven political parties that entered the German parliament following the election.

Obviously, opinion change and respectful consideration are not the same. That respondents change their opinions when and if their discussion partners change their opinions in the same direction is not necessarily the result of respectful considerations but may also reflect other social mechanisms such as conformity pressures. However, empirical studies on the mechanisms behind political discussion effects show that changes in discussion partners' opinions are usually precipitated both by the exchange of information and by social dynamics (cf. Partheymüller \& Schmitt-Beck, 2012; Schmitt-Beck \& Lup, 2013), making it reasonable to assume that at least part of the observed changes in opinion stem from discussion partners providing positive information about their new vote intention. Hence, we consider concordant opinion change among respondents and their discussion partners as indicative of the upper bound of respectful consideration, as it likely reflects social dynamics as well as the exchange of information consideration (cf. Polletta \& Gardner, 2018, p. 77).

Methodologically, we make use of the data's longitudinal structure and conduct a fixed-effects panel regression to analyze the determinants of opinion change. This method considers intra-individual dynamics over time (i.e., change within one respondent) instead of inter-individual differences (i.e., differences between respondents), thereby minimizing unobserved heterogeneity (cf. Imai \& Kim, 2019). To further minimize confounding effects of unobserved background variables that influence the opinions of both the respondents and their discussion partners, we control for intra-individual dynamics in campaign contacts and include wave fixed effects to account for campaign events.

The longitudinal structure of the data strengthens the validity of the findings in yet another way. While cross-sectional analyses of discussion networks struggle to differentiate whether a dyad's similarities in vote intention stem from mutual influence or self-selection into homogeneous networks, panel data allow us to avoid this problem and to hold any selection effects constant by considering only those discussion partners who were named when respondents provided information about their discussion network for the first time (adopted from Bello \& Rolfe, 2014). Subsequently, we trace whether the discussion partners mentioned in the initial wave were named again in later waves and how their vote intentions evolved. By observing this permanent set of discussion partners, we preclude any recomposition of the political discussion networks that might arise from selection effects, such as a trend towards homophily that may emerge during the run-up to the election, when political identities are salient. ${ }^{3}$ As respondents reported their initial discussion networks one year before the elections, their composition should not be influenced by the election campaign.

In addition to the dyadic information collected, the GLES Campaign Panel 2017 also inquired a range of individuallevel characteristics related to the political beliefs, attitudes, 
and behavior of the respondents. We operationalized the respondents' domain-related political involvement as their general political interest and measured group-related political involvement as the strength of identification with a political party. Both variables were collected in the first wave of the panel to avoid the aggravation of any biases through panel mortality and recoded to range between 0 and 1 . At 0.58 compared to 0.57 , the mean political interest in the panel is just slightly higher than in a random probability sample collected for the cross-sectional GLES survey after the 2017 election (Roßteutscher et al. 2019). Similarly, at 0.54 compared to 0.53 , the mean party identification strength in the panel is slightly higher than in the random probability sample. However, these deviations are substantively small and should therefore not impair the generalizability of our results.

\section{Results}

\section{Equal participation}

Who talks about politics and who does not? Do individuals who withdraw from the political domain also refrain from participating in everyday political discussions? To answer these questions, we ran a logistic regression analysis to explain who talked about politics at all during the year leading up to the national elections. As prior research has shown that better educated, younger people and men discuss politics more often, we include the level of education (categorical measure ranging from 1 to 5), age and sex as additional control variables, but will only discuss them when our results diverge from conventional wisdom (Conover et al., 2002; Nir, 2012). For each analysis, we also ran a second model including dummy variables for respondents' party identities. ${ }^{4}$

The findings confirm our expectation that citizens with high domain-related involvement are much more likely to discuss politics than the less involved. The predicted probabilities from the logistic regression analysis reported in Figure 2 show that almost every highly domaininvolved respondent (99 percent) talked about politics during the election campaign (see Appendix 3.1 for the full regression results). At the same time, only around 60 percent of the least involved discussed politics during the election campaign, suggesting that a large segment of this group is indeed excluded, or excludes itself, from political discussions. That a substantial portion of citizens with low domain involvement withdraws from political talk altogether is somewhat worrisome, given that we are observing political discussions in the highly conducive environment of an election campaign, which is designed to increase people's engagement with politics.

Figure $\mathbf{2}$ also illustrates that highly group-involved people are about six percentage points more likely to have talked about politics in the year leading up to the election than those without a group identity. As expected, this

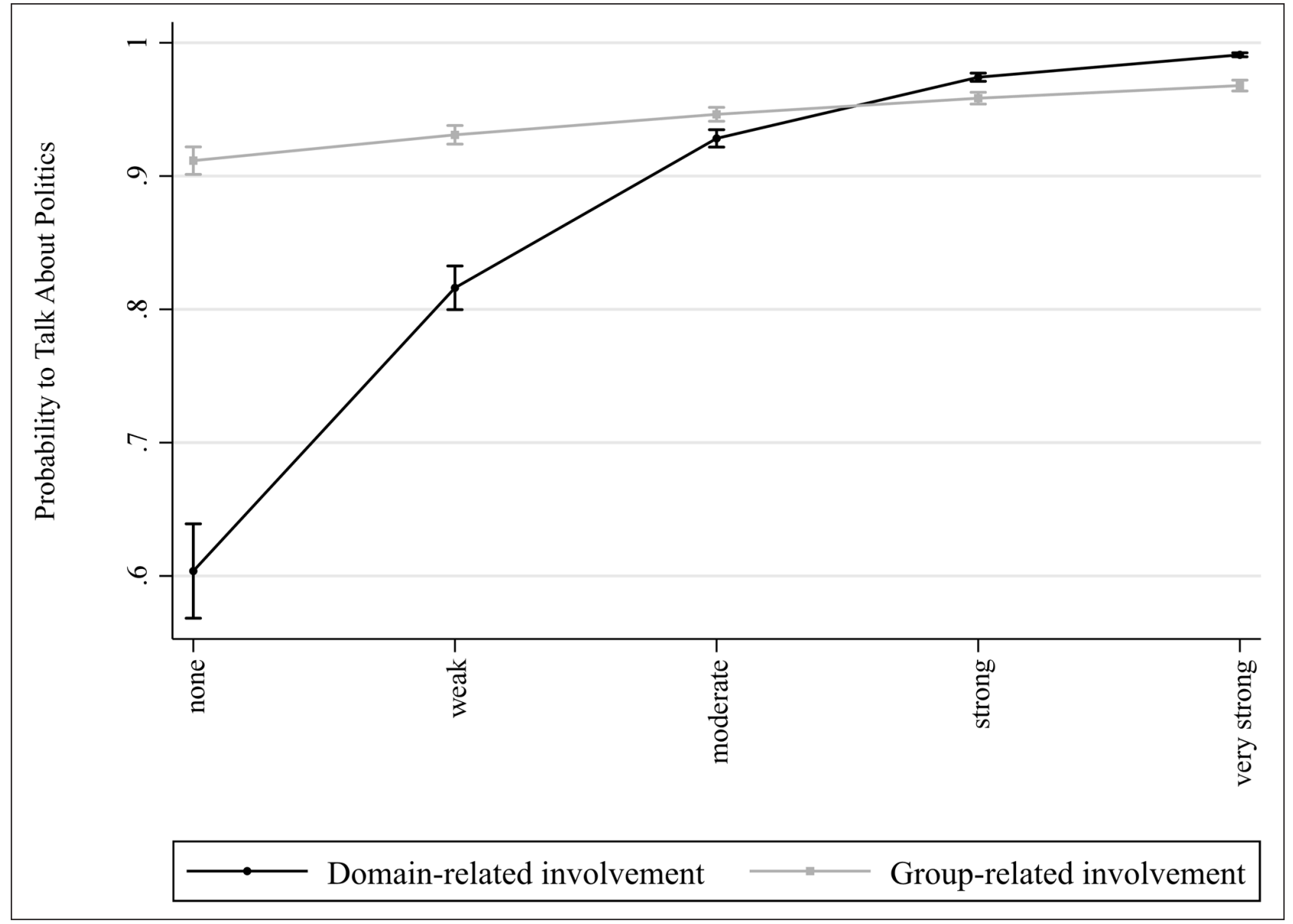

Figure 2: Predicted participation in political talk by levels of political involvement.

Note: Probabilities are predictions for men of average education and age; Source: ZA6804, Version 6.0.0. 
effect is substantively small compared to the influence of domain-related involvement. Among the least groupinvolved individuals, a high share of 91 percent discussed politics, which may be due to the election campaign context. Here, talking about politics at all during the year before the election may be a very low threshold that group-involved people could pass rather accidentally, for example, by telling someone about their group identity.

To further differentiate people who discussed politics regularly from those who only spoke about politics one or two times during the year leading up to the national elections, we analyze how domain-related and group-related political involvement affect how often and with how many different discussion partners respondents spoke about politics. Here, we expect the distinction between people who are highly domain-involved and the less involved to be even more marked, whereas the difference between partisans and non-partisans should remain comparatively small.

Figure 3 displays the predicted frequency of political discussions and the predicted network size for different levels of the two dimensions of political involvement (see Appendix 3.2 and 3.3. for full regression results). People who are highly involved in the political domain talk about politics every second day. In contrast, the least involved discuss politics only every third week on average. The predicted network size follows the same pattern. An average highly domain-involved individual has around 2.6 discussion partners in her network, while the least involved typically have only one discussion partner. Thus, people who have withdrawn from the political domain do not only have a lower chance to talk about politics in the first place, they also discuss politics notably less often and have quite limited discussion networks, even during an ongoing election campaign. This suggests that disadvantaged groups are much less likely to seize everyday opportunities for democratic deliberation than those already well-versed in the political domain.

With regard to group-related political involvement, Figure 3 illustrates that highly group-involved individuals discuss politics more frequently than those without a group identity. However, at about half a day per week, the difference is substantively small. In the same vein, people who strongly identify with a political group have around 0.4 discussion partners more in their networks than those without a group identity. Hence, group-related political involvement has a positive but substantively small effect on individual participation in informal political discussions. This effect is consistent across the more finegrained measures, suggesting that it is not entirely driven by the election campaign.

Unlike previous research, we find that older people are more likely to have talked about politics in the year before the election and discussed politics more frequently than younger people. Moreover, women who did talk about politics during the year before the election seem to do so more often and to have more discussion partners than men, although the difference in network size is negligible (see Appendix 3 for the full regression results). However,

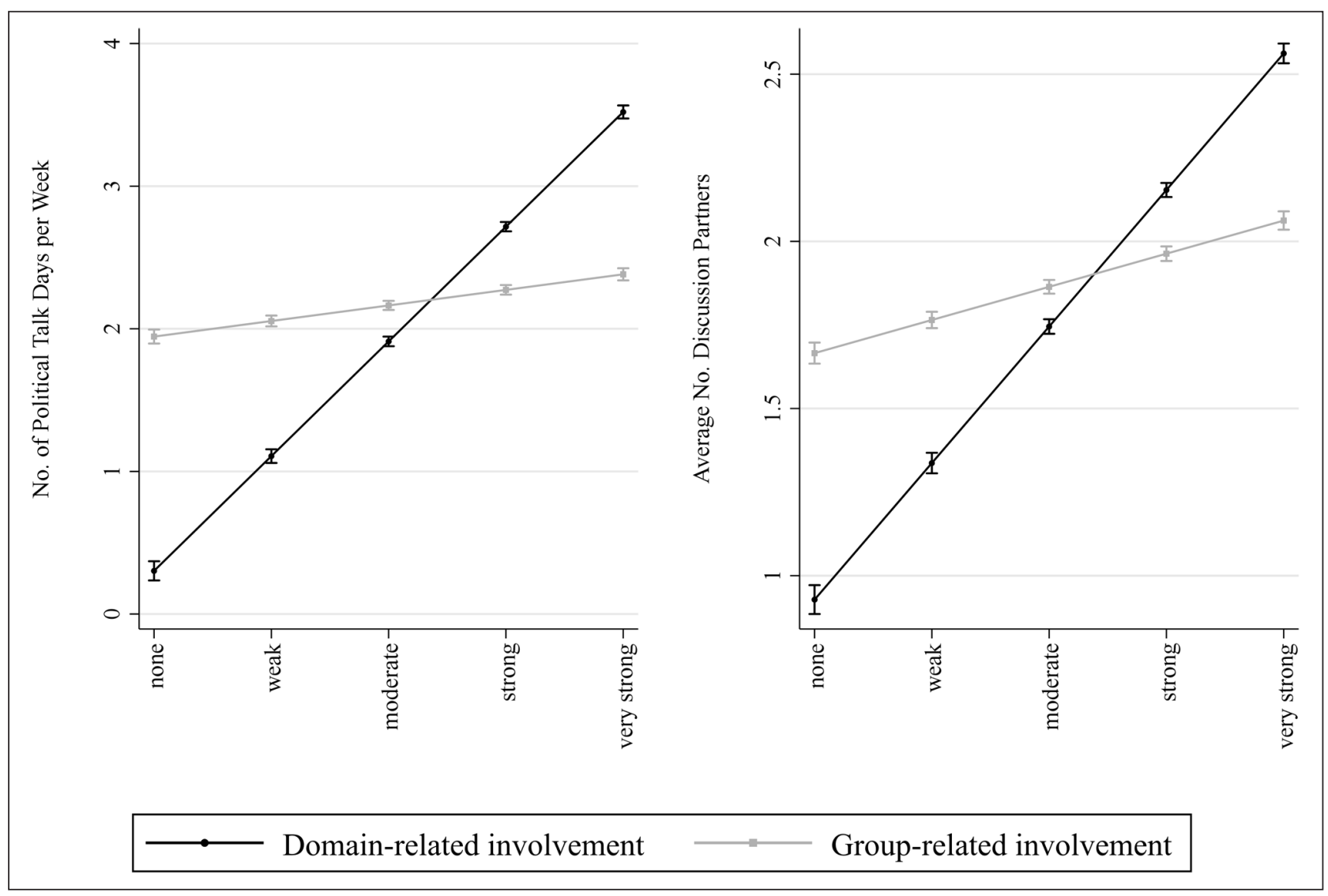

Figure 3: Predicted discussion frequency and discussion network size by levels of political involvement. Note: Probabilities are predictions for men of average education and age; Source: ZA6804, Version 6.0.0. 
the effects of the demographic variables are comparably small and do certainly not point to an exclusion of younger people or men from informal political discussions. People's partisanship does not influence their probability to discuss politics at all, but it does affect how often and with how many others they discuss politics. Controlling for strength of partisanship, identifiers of all parties except the AfD talk about politics less than those without a party identity, yet party identifiers tend to have slightly larger discussion networks than non-identifiers, likely for the same reasons as highly group-involved people.

In summary, domain-related and group-related involvement both increase participation in political talk, even though the effect of group-related involvement is much smaller. This seems to suggest that deliberation in informal political discussions is another form of participation reserved for politically engaged individuals. However, to understand the substantive impact of domainrelated political involvement, we also need to consider that complete withdrawal from the political domain is rare. Ninety-four percent of the respondents did talk about politics at least infrequently during the year leading up to the national election, indicating that only a small segment of the electorate withdrew entirely from political discussions, leastwise during an election campaign. With regard to the standard of equal participation, we therefore conclude that societal imbalances in political talk exist depending on the individual level of domain- and grouprelated political involvement, but that full exclusion from everyday political discussion is scarce.

\section{Inclusion of dissonant views}

We have shown that both domain-related and grouprelated political involvement have a positive impact on individuals' propensity to participate in political discussions. However, these dimensions should activate diametrically opposed patterns when it comes to the inclusion of dissonant voices in one's political discussion network. Highly domain-involved individuals should actively seek cross-cutting discussions, resulting in more heterogeneous political discussion networks compared to the less involved. On the other hand, those with high group-related involvement should avoid challenges to their group-related identities and therefore have relatively less heterogeneous political discussion networks than less group-involved individuals. In consequence, highly groupinvolved people should be most likely to actively exclude dissonant voices from their discussion networks.

To test this, we regress relative network heterogeneity, that is the percentage of dissonant views in a political discussion network, on domain-related and grouprelated political involvement (see Appendix 4.1 for the full regression results). The corresponding predicted probabilities displayed in Figure $\mathbf{4}$ only partly support

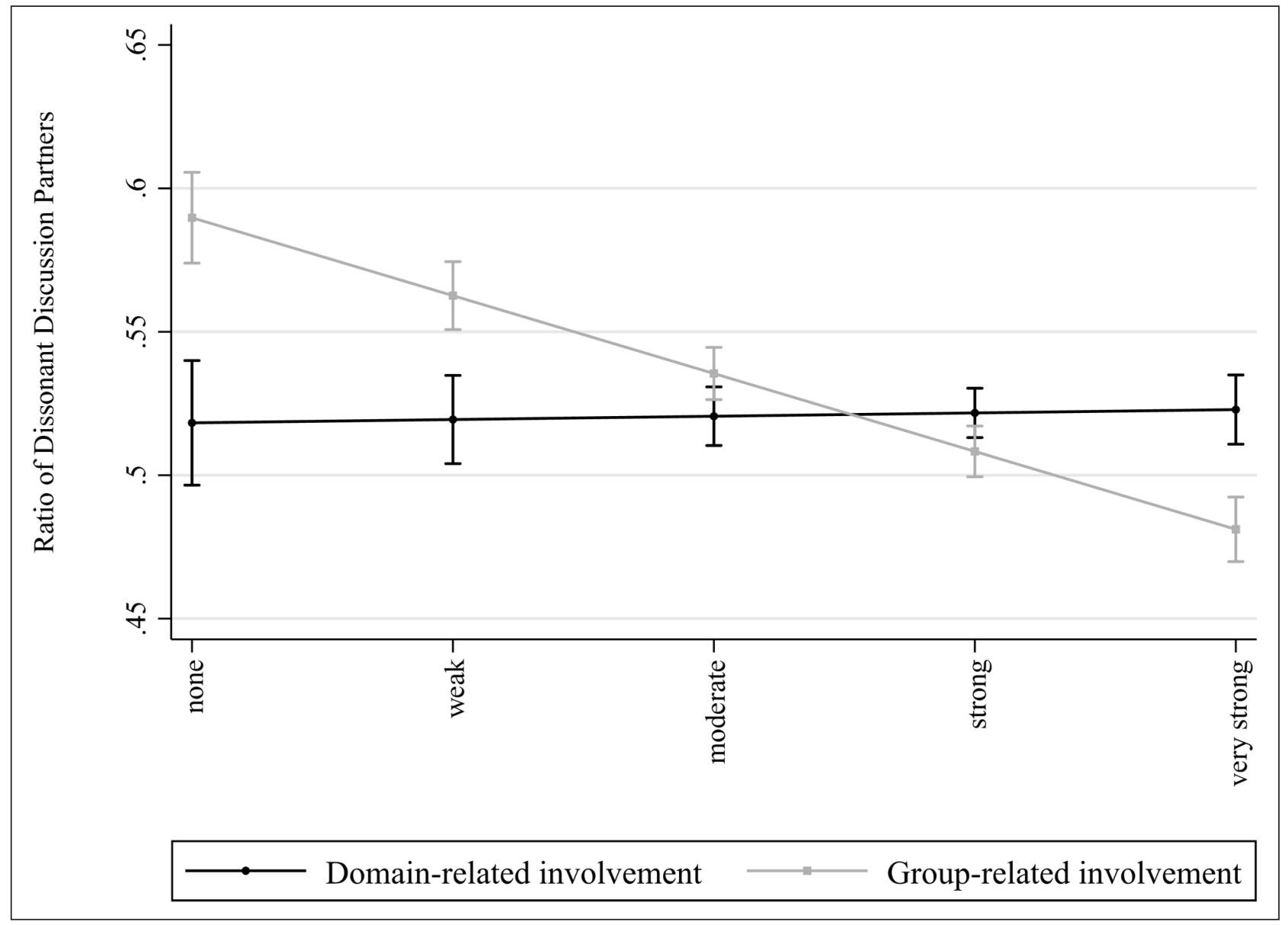

Figure 4: Predicted relative network heterogeneity by levels of political involvement. Note: Probabilities are predictions for men of average education and age; Source: ZA6804, Version 6.0.0. 
our expectations, as high domain-related involvement is not associated with more opinion diversity in political discussion networks compared to no domain-related involvement. On the bright side, despite the heightened competition during election campaigns, a lack of domainrelated involvement does not foster greater network homogeneity and, on average, around 50 percent of people's discussion partners have political views differing from their own.

The picture looks quite different for group-related political involvement. Here, the results confirm that group-involved people are more inclined to create exclusive political discussion networks. As Figure 4 illustrates, the discussion networks of highly groupinvolved individuals are around 11 percentage points less heterogeneous than the networks of the uninvolved. Our findings thus support the expectation that highly group-involved individuals have a stronger preference for politically like-minded discussion partners than people with no or low involvement. However, and again despite the heightened competition during election campaigns, even the most group-involved citizens still have around 48 percent dissonant voices in their political discussion networks, suggesting that they may find themselves in slightly biased discussion environments, but certainly not in exclusive filter bubbles (for a comprehensive discussion of different propensities to create heterogeneous discussion networks among German party identifiers, see Gärtner \& Wuttke, 2019).

To analyze the interplay between the size of discussion networks and their inclusivity, we also consider the impact of the two dimensions of political involvement on the absolute heterogeneity of discussion networks. The results of the regression analysis confirm the expectation that highly domain-involved individuals should be exposed to more dissonant voices because they have larger discussion networks. The corresponding predicted probabilities in Figure 5 show that highly domain-involved respondents have around half a dissonant discussion partner more in their network than uninvolved individuals. Considering that the respondents reported a maximum of three political discussion partners, this equals an increase in network size of at least 15 percent.

Regarding the impact of group-related involvement, we have shown that highly group-involved individuals have slightly larger discussion networks than those without a group identity. In consequence, even though group-related involvement reduces relative network heterogeneity, it could have the opposite effect on absolute network heterogeneity. The predicted probabilities in Figure $\mathbf{5}$ confirm this somewhat counterintuitive assessment, as highly group-involved individuals have around 0.18 dissonant discussion partners more than the uninvolved group. In absolute as in relative terms, identifiers of

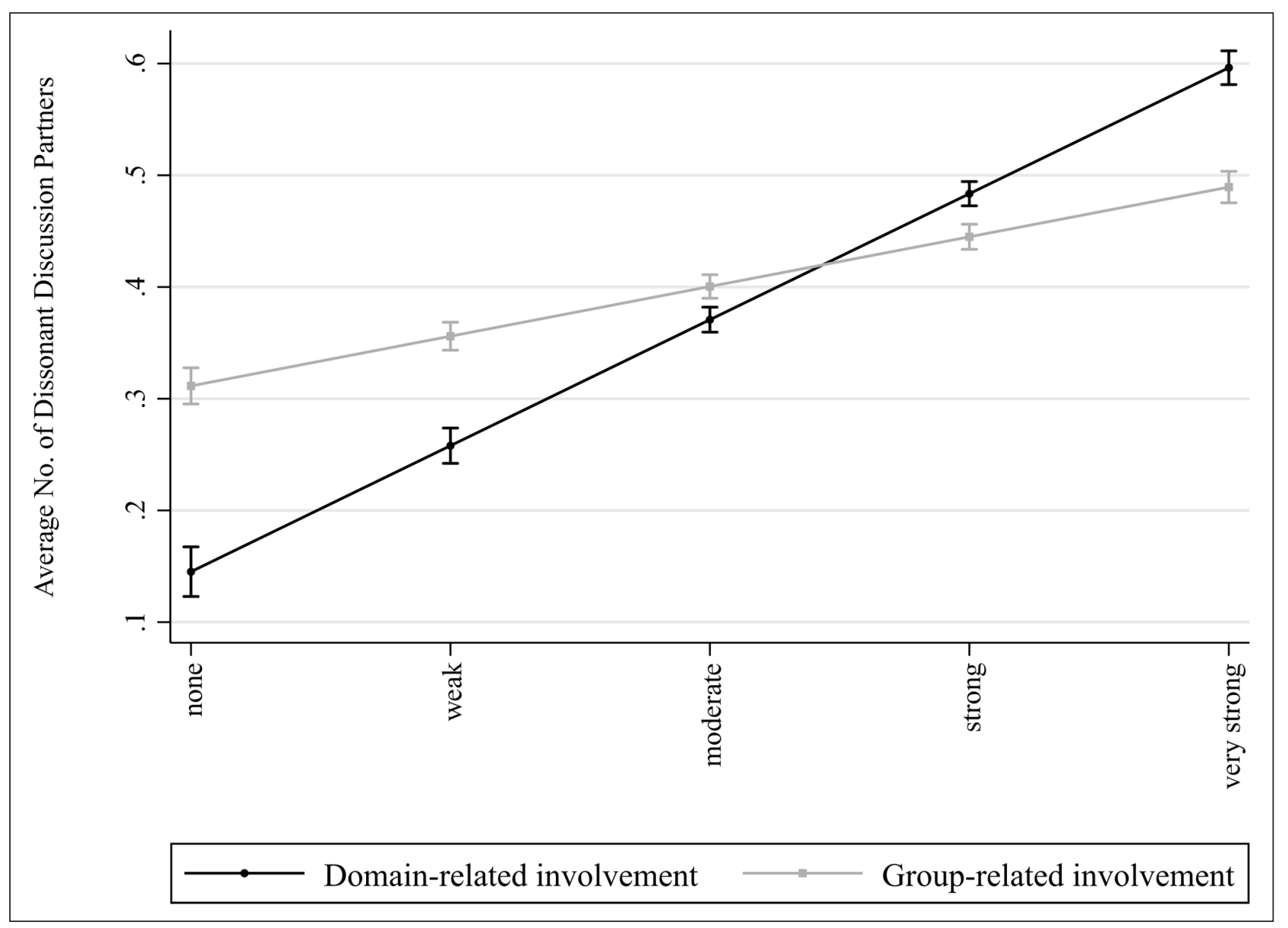

Figure 5: Predicted absolute network heterogeneity by levels of political involvement.

Note: Probabilities are predictions for men of average education and age; Source: ZA6804, Version 6.0.0. 
all parties except the AfD have more heterogeneous discussion networks when controlling for group-related involvement.

Overall, domain-related involvement does not have the expected positive effect on the relative inclusivity of discussion networks but increases the absolute inclusivity because highly domain-involved individuals have larger discussion networks. In contrast, group-related involvement promotes a relative exclusivity of discussion networks but also fosters absolute network inclusivity. Importantly, even the most group-involved individuals, who have the most homogeneous networks, still include around 48 percent dissonant voices in their networks. Taking into account the campaign context as well as the geographic and sociodemographic factors favoring the creation of homogeneous networks, a discussion environment in which half the voices represent dissonant opinions is a positive finding. Thus, our results suggest that even the people most likely to be politically polarized still do not exclude dissonant voices from their political discussion networks.

\section{Active listening and fair consideration}

However, the willingness to include dissonant views cannot further the goals of democratic deliberation if people who are highly involved in the political domain would consider it unnecessary to listen to other viewpoints, as their opinions ostensibly factor in all relevant facts, or if the highly group-involved countered any dissonant information with motivated reasoning. In the following, we analyze how the two dimensions of political involvement influence the number of opinion changes people perceived in their discussion networks, before narrowing our focus from people's networks to a dyadic perspective to test how domain- and group-related involvement affected people's propensity to change their own vote intention in reaction to changes in their discussion partners' vote intentions.

To assess whether domain-related or group-related political involvement decrease active listening, we first analyze their impact on the total number of perceived opinion changes, which must be between 0 and 21 . Because the probability to perceive an opinion change increases with the number of discussion partners, we control for network size (see Appendix 5 for full regression results). Figure 6 shows that highly domain-involved people perceive around 1.4 opinion changes more in their political discussion networks than individuals who have withdrawn from the political domain. This effect seems small compared to the number of possible opinion changes, but is in fact substantial, as perceived opinion changes are relatively rare. Despite the ongoing election campaign, which should make respondents' vote intentions more salient, an average respondent only reports around 3.3 opinion changes in her discussion network

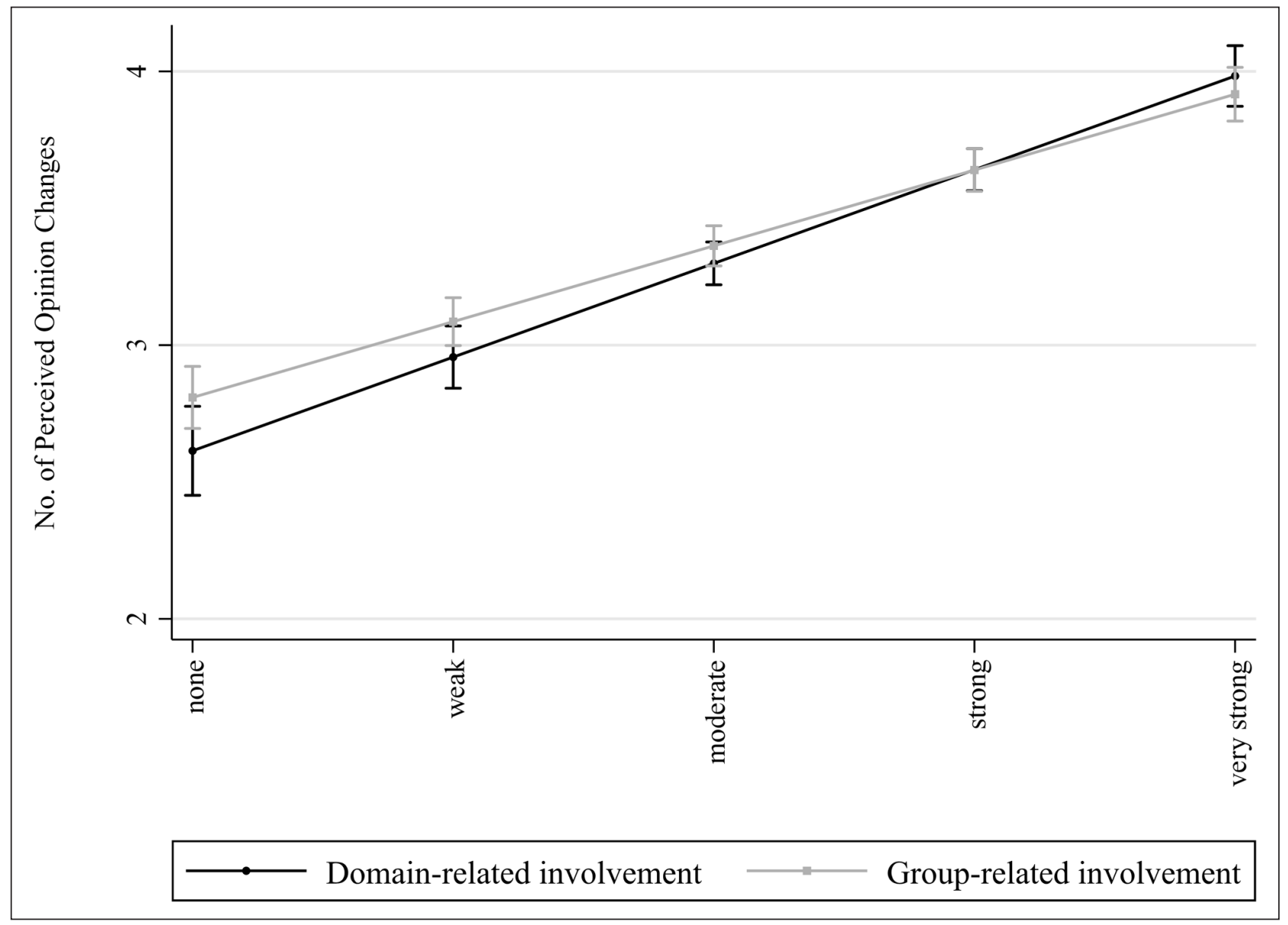

Figure 6: Predicted perceived number of opinion changes across all waves by levels of political involvement. Note: Probabilities are predictions for men of average education and age; Source: ZA6804, Version 6.0.0. 
across all waves, and around a third of the respondents report no opinion changes at all. Hence, highly domaininvolved individuals seem more rather than less likely than those who are not involved in the political domain to actively listen to their discussion partners. These findings lend credence to our first hypothesis that domainrelated involvement enhances active listening because highly domain-involved people strive to improve their understanding of the political domain. Conversely, those who have withdrawn from the political domain seem to have a harder time pinning down changes in the political preferences of their discussion partners, indicating that limited domain-related political involvement inhibits the goals of democratic deliberation in everyday political encounters.

More surprisingly, group-related involvement also has a positive influence on the perceived number of opinion changes. Highly group-involved people reported 1.1 opinion changes more in their discussion networks than those who do not identify with a political group. In comparison to the average perception of 3.3 opinion changes, this equals an increase of one third. Thus, against our expectations, group-related involvement does not seem to impede active listening. Nevertheless, motivated reasoning may still set in when it comes to the fair consideration of dissonant arguments.

So, does active listening suggest that people also fairly consider dissonant opinions? To test whether the two dimensions of political involvement moderate respondents' likelihood to change their vote intentions when one of their discussion partners changes her vote intention, we ran a fixed-effects logistic regression analysis on changes in respondents' party vote intention. The main independent variable was changes in discussion partners' vote intentions and we included an interaction term for each dimension of political involvement. To reiterate, we only consider concordant changes in vote intention, which we argue are indicative of fair consideration. For a respondent to be included in the model, at least one of her discussion partners must have changed her vote intention to a party not preferred by the respondent.

The analysis was run separately for each party, controlling for the respective survey wave (wave controls) and the party identities of respondents. Our research design eliminates the influence of activation and selection effects, but election campaigns are still designed to change voters' opinions. To ensure that changes in vote intention stem from changes in the preferences of discussion partners rather than campaign stimuli that several network members were exposed to, we also controlled for respondents' campaign contacts (e.g., Schoen et al., 2017). Because the fixed component of our model inhibits the estimation of predicted probabilities or average marginal effects, which would be the standard for interpreting logistic regressions, we report odds ratios instead (cf. Allison, 1999; Pforr, 2014). The discussion partners are ordered by discussion frequency, that is the respondent discussed politics most frequently with Discussant 1, followed by Discussant 2 and Discussant 3.
Table 2 shows the results of the fixed-effects logistic regression. For reasons of concision, we do not display the control variables, but respondents who identified with a party or were contacted during the campaign were expectedly more likely to change their vote intentions to the respective party (see Appendix 6 for the full regression results). In general, respondents were between 1.4 and 2.5 times more likely to change their vote intention to a party if their most frequent political discussion partner changed her vote intention to the same party (see Appendix 7 for regression main effects). In other words, we see some opinion change, which hints at the occurrence of respectful consideration. However, the interaction with domain-related involvement does not pass conventional levels of statistical significance, suggesting that domaininvolved individuals are neither more nor less likely than those not involved in the political domain to change their opinions in light of positive information offered by a discussion partner. Thus, highly-domain involved people are not harder to sway because they possess more prior information about the political domain, but are equally open to considering dissonant views.

With regard to group-related involvement, the results in Table $\mathbf{2}$ do not support our expectation that highly group-involved individuals should be prone to motivated reasoning and thus less likely than those without a group identity to change their vote intentions based on positive cues from their discussion partners. Only two of the interaction terms for group-related involvement are statistically significant and even though the coefficients point in the expected direction, these results do not indicate a systematic influence of group-related involvement on individuals' likelihood to adopt the political preferences of their discussion partners. Thus, even though highly groupinvolved people prefer to talk to like-minded discussion partners, they do not usually dismiss the dissonant views in their political discussion networks out of hand.

Altogether, both domain- and group-related political involvement foster active listening and neither systematically decreases the influence of political talk on political preferences, suggesting that neither decreases the likelihood that people will fairly consider dissonant views. This finding can be considered good news for democratic deliberation in everyday political talk, as it indicates that even the most group-involved individuals actively listen and usually give fair consideration to dissonant perspectives. Although these results rely on proxy measures for active listening and fair consideration and thus have to be considered suggestive rather than definitive, our findings offer no indication that people routinely violate standards of mutual respect in their informal political discussions.

Considering all three core standards of democratic deliberation that we could measure, we are left with a surprisingly encouraging picture. Individuals who have withdrawn from the political domain may not discuss politics often and with many different people, but only 6 percent of the respondents never participate in political discussions. Thus, even among the least domain-involved individuals, who are likely to be politically disadvantaged, 
Table 2: The influence of changes in discussants' vote intentions on changes in the respondent's vote intention.

\begin{tabular}{|c|c|c|c|c|c|c|}
\hline & $\mathrm{CDU} / \mathrm{CSU}$ & SPD & FDP & Greens & Left & AfD \\
\hline \multirow[t]{2}{*}{ Discussant 1} & $1.78^{*}$ & $3.31^{* * *}$ & 1.91 & 0.69 & 1.82 & 1.68 \\
\hline & $(0.43)$ & $(0.72)$ & $(0.84)$ & $(0.29)$ & $(0.64)$ & $(0.57)$ \\
\hline \multirow[t]{2}{*}{ Discussant 2} & 1.06 & 1.27 & 1.48 & 0.70 & 0.87 & $3.04^{*}$ \\
\hline & $(0.34)$ & $(0.39)$ & $(0.89)$ & $(0.41)$ & $(0.46)$ & $(1.34)$ \\
\hline \multirow[t]{2}{*}{ Discussant 3} & $3.19^{* *}$ & 0.81 & 0.58 & 2.25 & 2.16 & 0.51 \\
\hline & $(1.32)$ & $(0.30)$ & $(0.47)$ & $(1.62)$ & $(1.39)$ & $(0.28)$ \\
\hline \multicolumn{7}{|c|}{ Interaction with domain-related involvement } \\
\hline \multirow[t]{2}{*}{ *Discussant 1} & 0.66 & 1.02 & 0.99 & 2.36 & 2.08 & 1.40 \\
\hline & $(0.22)$ & $(0.29)$ & $(0.57)$ & $(1.15)$ & $(0.95)$ & $(0.67)$ \\
\hline \multirow[t]{2}{*}{ *Discussant 2} & 1.96 & 1.36 & 0.93 & 1.09 & 3.33 & 0.98 \\
\hline & $(0.83)$ & $(0.51)$ & $(0.79)$ & $(0.75)$ & $(2.39)$ & $(0.58)$ \\
\hline \multirow[t]{2}{*}{ *Discussant 3} & 0.59 & 0.82 & 5.66 & 0.72 & 1.30 & 2.35 \\
\hline & $(0.30)$ & $(0.39)$ & $(5.72)$ & $(0.66)$ & $(1.07)$ & $(1.67)$ \\
\hline \multicolumn{7}{|c|}{ Interaction with group-related involvement } \\
\hline \multirow[t]{2}{*}{ *Discussant 1} & 1.06 & $0.47^{* *}$ & 1.14 & 2.05 & 0.77 & 1.07 \\
\hline & $(0.27)$ & $(0.11)$ & $(0.49)$ & $(0.90)$ & $(0.27)$ & $(0.36)$ \\
\hline \multirow[t]{2}{*}{ *Discussant 2} & 0.60 & 0.80 & 0.98 & 2.50 & 0.68 & $0.29 * *$ \\
\hline & (0.19) & $(0.26)$ & $(0.60)$ & $(1.44)$ & $(0.31)$ & $(0.13)$ \\
\hline \multirow[t]{2}{*}{ *Discussant 3} & 0.56 & 1.96 & 0.31 & 0.71 & 0.53 & 1.11 \\
\hline & $(0.24)$ & $(0.73)$ & $(0.22)$ & $(0.55)$ & $(0.29)$ & $(0.58)$ \\
\hline Wave Controls & Yes & Yes & Yes & Yes & Yes & Yes \\
\hline Lagged DV & No & No & No & No & No & No \\
\hline $\mathrm{N}$ & 13,070 & 17,983 & 9,724 & 10,352 & 11,666 & 8,093 \\
\hline Groups & 2309 & 3137 & 1700 & 1791 & 1987 & 1428 \\
\hline
\end{tabular}

Notes: Reported are odds ratios from fixed-effects logistic regressions, run separately for each party; Discussant 1-3 is the person whom the respondents talks most, second-most or third-most frequently with. Effects of discussant variables denote the effect of intra-individual dynamics in voting intentions towards one party on the changes in the respondent's inclinations to vote for that party; *: p < 0.05, ${ }^{* *}:$ p $<0.01,{ }^{* * *}: \mathrm{p}<0.001$.

exclusion from informal opportunities for democratic deliberation is rare, leastwise during an election campaign. On the other hand, highly group-involved individuals may prefer to discuss politics with like-minded people, but nearly half of their discussion partners have dissonant political preferences and their views are not dismissed out of hand. Hence, even the most group-involved individuals do not exclude different-minded people from their political discussions, despite the high salience of group identities during an ongoing election campaign. What is more, they mostly consider different viewpoints as fairly as individuals who are not attached to a political group. All in all, while democratic deliberation in everyday political discussions is far from guaranteed, it is also not a hopeless case, as people generally uphold the standards of equality, inclusion, and mutual respect in their everyday political encounters, even outside of formal deliberative settings.

\section{Conclusion}

Informal political exchanges between ordinary people are the most prevalent opportunity for democratic deliberation in the broader public and are credited with a range of positive effects from honing people's deliberative skills, over enabling the formation of considered preferences and stable political identities, to encouraging political participation, tolerance, and civic-mindedness. Whether such positive effects come to pass depends on the democratic and deliberative quality of informal political discussions. To assess the potential for democratic deliberation in the broader public and to test how individual political involvement affects compliance with its core standards, we conceptualized democratic deliberation in informal political exchanges as a multi-step process, comprising equal participation in political talk, the inclusion of dissonant views, the fair consideration of other viewpoints, and reason-giving. 
Our results suggest that most everyday political discussions cannot fully meet the standards of formal democratic deliberation, but that informal political exchanges nonetheless offer an opportunity to learn about novel arguments, to enhance mutual understanding and respect, and to practice for more demanding modes of deliberative democracy. Importantly, the potential for democratic deliberation is not undermined by individuals' domain- and group-related political involvement, even though the two dimensions do affect equal participation and network inclusivity in different ways. That their effects are distinct illustrates the importance of conceptualizing compliance with the standards of democratic deliberation in informal political discussions as a multi-step process that may fail at any one step. It is only because the observed political discussions largely satisfy the standards of equality, inclusion, and mutual respect that we can conclude that everyday political talk is more democratic and deliberative than anticipated in light of rising political disenchantment and increasing partisan polarization.

In interpreting our results, we have to carefully consider the election campaign context. On the one hand, we cannot preclude that participation and listening in particular are less prevalent when parties are not competing for people's attention. Hence, the share of people who do not talk about politics at all may be larger than 6 percent in between election campaigns. Potential sampling biases may further have exacerbated the underestimation of citizens who withdraw from the political domain because people who are less engaged with the political domain may also be less likely to respond to political surveys. What is more, the inclination to discuss politics may be distributed even more unequally when there is no campaign that arouses citizens' interest. On the other hand, the campaign context can be considered a leastlikely case for network diversity, which strengthens our contention that even the most polarized individuals do not exclude dissonant voices from their political discussions.

Our conclusions are necessarily limited by the fact that we have no information about our respondents' motivation to talk about politics or the content of their political discussions. This is particularly problematic for measuring active listening and the respectful consideration of dissonant opinions, for which we could estimate upper bounds only. Although we can reasonably assume that opinion changes are the result of information exchanges as well as social dynamics, we do not know how many opinion changes are induced by the former versus the latter. Thus, the estimated upper border may be considerably higher than the actual level of respectful considerations, belying our relatively positive conclusion. Our inability to differentiate between opinion changes predicated on information provision or on social pressure may also have implications for our findings on political involvement. The somewhat surprising result that highly domain-involved people are as likely to change their vote intentions as people who have largely withdrawn from the political domain, for instance, would be less surprising if people with high domain-related involvement mainly changed their opinions based on positive information received from their discussion partners, whereas people with low domain-related involvement mostly changed their vote intentions to conform to their discussants' expectations.

\section{Notes}

${ }^{1}$ For detailed information on the study design, question wording and scaling, please refer to the GESIS Datenbestandskatalog (ZA6804).

${ }^{2}$ For instance, it is clear that a respondent's spouse with the first name initial " $\mathrm{A}$ " and the last name initial "K" from survey wave 1 is the same person as spouse "A.K." from wave 2. Four percent of discussion partners shared identical identifying information and were discarded.

${ }^{3}$ Even though we hold discussion networks constant, self-selection might still exert effects on the networks we observe, because respondents might remove conversation partners they disagree with from their initial discussion networks. Even if this is the case, however, this effect would not confound the reported conversation effects, because conversation partners who were removed from the network are not included in the respective survey waves and therefore cannot bias regression coefficients.

${ }^{4}$ All results were estimated using the GLES Campaign Panel 2017 (ZA6804, Version 6.0.0).

${ }^{5}$ There are more respondents who named at least one conversation partner than respondents who indicated two or three conversation partners. Accordingly, the sample sizes vary considerably between the groups, with about one-half of the respondents naming a second and about one fourth naming a third conversation partner. Because we report effects for each conversation partner on the entire sample of respondents, the estimated effect for non-existent conversation partners is zero for respondents with small conversation networks. Similar to the distinction of intent-to-treat and complier-average-effect in experiments, in interpreting the analyses we should keep in mind that the estimate coefficients for Discussants 2 and 3 denote average effects for the entire sample of respondents and underestimate the effects on respondents who actually had conversations with two or three conversation partners.

\section{Data Accessibility Statement}

Replication material (data, Stata syntaxes) for all analyses is available at https://doi.org/10.17605/OSF.IO/VUGPM.

\section{Acknowledgements}

We thank two anonymous reviewers for their critical reading of the manuscript and their detailed and constructive suggestions, which helped us to considerably improve the paper. We also thank the editors of this special issue for their editorial guidance and competent management of the submission process.

\section{Additional File}

The additional file for this article can be found as follows: 
- Appendix. Tables A1 to A7. DOI: https://doi. org/10.16997/jdd.983.s1

\section{Funding Information}

This work was supported by the German Research Foundation [SCHO 1358/4-3].

\section{Competing Interests}

The authors have no competing interests to declare.

\section{Author Contributions}

L. Gärtner, A. Wuttke, and H. Schoen collaboratively conceived this paper. L. Gärtner wrote the initial draft, designed and performed the cross-sectional regression analyses, and visualized and interpreted the corresponding results. A. Wuttke designed and performed the panel analyses, and prepared the replication material. All authors critically revised and edited the initial draft and have provided final approval of the version to be published.

\section{References}

Allison, P. D. (1999). Comparing Logit and Probit Coefficients Across Groups. Sociological Methods \& Research, 28(2), 186-208. DOI: https://doi. org $/ 10.1177 / 0049124199028002003$

Armingeon, K., \& Schädel, L. (2015). Social Inequality in Political Participation: The Dark Sides of Individualisation. West European Politics, 38(1), 1-27. DOI: https://doi.org/10.1080/01402382.2014.9293 41

Bächtiger, A., Dryzek, J. S., Mansbridge, J., \& Warren, M. (2018). Deliberative Democracy: An Introduction. In Andre Bächtiger, J., Dryzek, S., Mansbridge, J., \& Warren, M. (Eds.), The Oxford Handbook of Deliberative Democracy (pp. 1-35). Oxford University Press. DOI: https://doi.org/10.1093/ oxfordhb/9780198747369.013.50

Bächtiger, A., \& Parkinson, J. (2019). Mapping and Measuring Deliberation: Towards a New Deliberative Quality. Oxford University Press. DOI: https://doi. org/10.1093/oso/9780199672196.001.0001

Barnidge, M. (2017). Exposure to Political Disagreement in Social Media Versus Face-to-Face and Anonymous Online Settings. Political Communication, 34(2), 302321. DOI: https://doi.org/10.1080/10584609.2016.12 35639

Bello, J., \& Rolfe, M. (2014). Is influence mightier than selection? Forging agreement in political discussion networks during a campaign. Special Issue on Political Networks, 36, 134-146. DOI: https://doi. org/10.1016/j.socnet.2013.06.001

Bohman, J. (1996). Public Deliberation: Plurality, Complexity, and Democracy. MIT Press.

Brannon, L. A., Tagler, M. J., \& Eagly, A. H. (2007). The moderating role of attitude strength in selective exposure to information. Journal of Experimental Social Psychology, 43(4), 611-617. DOI: https://doi. org/10.1016/j.jesp.2006.05.001

Conover, P. J., \& Miller, P. R. (2018). Taking Everyday Political Talk Seriously. In Andre Bächtiger, J., Dryzek,
S., Mansbridge, J., \& Warren, M. (Eds.), The Oxford Handbook of Deliberative Democracy (pp. 378-391). Oxford University Press. DOI: https://doi.org/10.1093/ oxfordhb/9780198747369.013.12

Conover, P. J., \& Searing, D. D. (2005). Studying "Everyday Political Talk" in the Deliberative System. Acta Politica, 4O(3), 269-283. DOI: https://doi.org/10.1057/ palgrave.ap.5500113

Conover, P. J., Searing, D. D., \& Crewe, I. M. (2002). The Deliberative Potential of Political Discussion. British Journal of Political Science, 32(1), 21-62. DOI: https:// doi.org/10.1017/S0007123402000029

Converse, P. E. (1964). The Nature of Belief Systems in Mass Publics. In D. E. Apter (Ed.), Ideology and Discontent (pp. 206-261). Free Press.

Dalton, R. J. (2007). Partisan mobilization, cognitive mobilization and the changing American electorate. Electoral Studies, 26(2), 274-286. DOI: https://doi. org/10.1016/j.electstud.2006.04.009

Dalton, R. J. (2012). Apartisans and the changing German electorate. Special Symposium: Germany's Federal Election September 2009, 31(1), 35-45. DOI: https:// doi.org/10.1016/j.electstud.2011.06.005

Dassonneville, R., Hooghe, M., \& Vanhoutte, B. (2012). Age, Period and Cohort Effects in the Decline of Party Identification in Germany: An Analysis of a Two Decade Panel Study in Germany (1992-2009). German Politics, 21(2), 209-227. DOI: https://doi.org/10.1080/09644 008.2012 .679659

Dilliplane, S. (2014). Activation, Conversion, or Reinforcement? The Impact of Partisan News Exposure on Vote Choice. American Journal of Political Science, 58(1), 79-94. DOI: https://doi.org/10.1111/ajps.12046

Ditto, P. H., \& Lopez, D. F. (1992). Motivated skepticism: Use of differential decision criteria for preferred and nonpreferred conclusions. Journal of Personality and Social Psychology, 63(4), 568-584. DOI: https://doi. org/10.1037/0022-3514.63.4.568

Druckman, J. N. (2012). The Politics of Motivation. Critical Review, 24(2), 199-216. DOI: https://doi.org/1 0.1080/08913811.2012.711022

Dryzek, J. S. (2000). Deliberative Democracy and Beyond: Liberals, Critics, Contestations. Oxford University Press.

Dubois, E., \& Blank, G. (2018). The echo chamber is overstated: The moderating effect of political interest and diverse media. Information, Communication \& Society, 21(5), 729-745. DOI: https://doi.org/10.1080 /1369118X.2018.1428656

Eveland, W. P., Jr., Morey, A. C., \& Hutchens, M. J. (2011). Beyond Deliberation: New Directions for the Study of Informal Political Conversation from a Communication Perspective. Journal of Communication, 61(6), 1082-1103. DOI: https://doi.org/10.1111/j.14602466.2011.01598.x

Foa, R. S., \& Mounk, Y. (2017). The Signs of Deconsolidation. Journal of Democracy, 28(1), 5-15. DOI: https://doi.org/10.1353/jod.2017.0000

Gallego, A. (2007). Unequal Political Participation in Europe. International Journal of Sociology, 37(4), 10-25. DOI: https://doi.org/10.2753/IJS0020-7659370401 
Gärtner, L., \& Wuttke, A. (2019). Eingeschlossen in der Filter Bubble? Politische Kommunikationsnetzwerke im Wahlkampf. In Roßteutscher, S., Schmitt-Beck, R., Schoen, H., Weßels, B., \& Wolf, C. (Eds.), Die Bundestagswahl 2017 (Vol. 3, pp. 101-112). Nomos. DOI: https://doi.org/10.5771/9783845287607

Gastil, J., Black, L. W., Deess, E. P., \& Leighter, J. (2008). From Group Member to Democratic Citizen: How Deliberating with Fellow Jurors Reshapes Civic Attitudes. Human Communication Research, 34, 137-169. DOI: https://doi.org/10.1111/j.14682958.2007.00316.x

Gastil, J., Deess, E. P., Weiser, P. J., \& Simmons, C. (2010). The Jury and Democracy: How Jury Deliberation Promotes Civic Engagement and Political Participation. Oxford University Press.

Gerber, M., Bächtiger, A., Shikano, S., Reber, S., \& Rohr, S. (2018). Deliberative Abilities and Influence in a Transnational Deliberative Poll (EuroPolis). British Journal of Political Science, 48(4), 1093-1118. DOI: https://doi.org/10.1017/S0007123416000144

Goodliffe, G. (2012). The Price of Disengagement: Radical Populism in France and Germany. Journal of Contemporary European Studies, 20(2), 137-160. DOI: https://doi.org/10.1080/14782804.2012.685388

Goren, P. (2005). Party Identification and Core Political Values. American Journal of Political Science, 49(4), 881-896. DOI: https://doi.org/10.1111/j.15405907.2005.00161.x

Green, D., Palmquist, B., \& Schickler, E. (2002). Partisan Hearts and Minds: Political Parties and Social Identities of Voters. Yale University Press.

Gutmann, A., \& Thompson, D. (1996). Democracy and Disagreement. Harvard University Press.

Gutmann, A., \& Thompson, D. (1999). Democratic Disagreement. In S. Macedo (Ed.), Deliberative Politics: Essays on Democracy and Disagreement (pp. 243-279). Oxford University Press.

Gutmann, A., \& Thompson, D. (2004). Why Deliberative Democracy? Princeton University Press. DOI: https:// doi.org/10.1515/9781400826339

Gutmann, A., \& Thompson, D. (2014). The Spirit of Compromise: Why Governing Demands It and Campaigning Undermines It. Princeton University Press. DOI: https://doi.org/10.1515/9781400851249

Gutmann, A., \& Thompson, D. (2018). Reflections on Deliberative Democracy: When Theory Meets Practice. In André Bächtiger, J., Dryzek, S., Mansbridge, J., \& Warren, M. (Eds.), The Oxford Handbook of Deliberative Democracy. Oxford University Press. DOI: https://doi. org/10.1093/oxfordhb/9780198747369.013.44

Habermas, J. (1990). Moral Consciousness and Communicative Action (C. Lenhardt \& S. Weber Nicholsen, Trans.). MIT Press.

Habermas, J. (2006). Political Communication in Media Society: Does Democracy Still Enjoy an Epistemic Dimension? The Impact of Normative Theory on Empirical Research1. Communication Theory, 16(4), 411-426. DOI: https://doi.org/10.1111/j.14682885.2006.00280.x
Habermas, J. (2008). Between Naturalism and Religion(C. Conan, Trans.). Polity Press.

Huckfeldt, R. R., \& Sprague, J. (1995). Citizens, Politics and Social Communication: Information and Influence in an Election Campaign. Cambridge University Press. DOI: https://doi.org/10.1017/CBO9780511664113

Huddy, L., \& Khatib, N. (2007). American Patriotism, National Identity, and Political Involvement. American Journal of Political Science, 51(1), 63-77. DOI: https:// doi.org/10.1111/j.1540-5907.2007.00237.x

Iglic, H., \& Font Fábregas, J. (2008). Social Networks. In Van Deth, J. W., Ramón, J., \& Westholm, A. (Eds.), Citizenship and Involvement in European Democracies: A Comparative Analysis. Routledge.

Imai, K., \& Kim, I. S. (2019). When Should We Use Unit Fixed Effects Regression Models for Causal Inference with Longitudinal Data? American Journal of Political Science, 63(2), 467-490. DOI: https://doi. org/10.1111/ajps.12417

Iyengar, S., Hahn, K. S., Krosnick, J. A., \& Walker, J. (2008). Selective Exposure to Campaign Communication: The Role of Anticipated Agreement and Issue Public Membership. The Journal of Politics, 70(1), 186-200. DOI: https://doi.org/10.1017/S0022381607080139

Iyengar, S., Lelkes, Y., Levendusky, M., Malhotra, N., \& Westwood, S. J. (2019). The Origins and Consequences of Affective Polarization in the United States. Annual Review of Political Science, 22(1), 129-146.DOI: https:// doi.org/10.1146/annurev-polisci-051117-073034

Klein, E. (2020). Why We're Polarized. Simon \& Schuster.

Klofstad, C. A., Sokhey, A. E., \& McClurg, S. D. (2013). Disagreeing about Disagreement: How Conflict in Social Networks Affects Political Behavior. American Journal of Political Science, 57(1), 120-134. DOI: https://doi.org/10.1111/j.1540-5907.2012.00620.x

Knight, J., \& Johnson, J. (1997). What Sort of Political Equality does Democratic Deliberation Require? In Bohman, J., \& Rehg, W. (Eds.), Deliberative Democracy: Essays on Reason and Politics (pp. 279-319). MIT Press.

Knobloch, K. R. (2011). Public Sphere Alienation. Javnost - The Public, 18(4), 21-37. DOI: https://doi.org/10.10 80/13183222.2011.11009065

Knobloch, K. R., \& Gastil, J. (2014). Civic (Re) socialisation: The Educative Effects of Deliberative Participation. Politics, 35(2), 183-200. DOI: https:// doi.org/10.1111/1467-9256.12069

Krosnick, J. A., \& Petty, R. E. (1995). Attitude strength: An overview. In Attitude strength: Antecedents and consequences. (pp. 1-24). Lawrence Erlbaum Associates, Inc.

Mansbridge, J. (1999). Everyday Talk in the Deliberative System. In S. Macedo (Ed.), Deliberative Politics: Essays on Democracy and Disagreement (pp. 211-239). Oxford University Press.

Mansbridge, J. (2015). A Minimalist Definition of Deliberation. In Heller, P., \& Rao, V. (Eds.), Deliberation and Development (pp. 27-49). World Bank. DOI: https://doi.org/10.1596/978-1-4648-0501-1_ch2

Morrell, M. (2018). Listening and Deliberation. In André Bächtiger, J., Dryzek, S., Mansbridge, J., \& Warren, M. 
(Eds.), The Oxford Handbook of Deliberative Democracy (pp. 237-250). Oxford University Press. DOI: https:// doi.org/10.1093/oxfordhb/9780198747369.013.55

Mounk, Y. (2018). The People vs. Democracy: Why Our Freedom Is in Danger and How to Save It. Harvard University Press. DOI: https://doi. org/10.4159/9780674984776

Neblo, M. A. (2015). Deliberative Democracy Between Theory and Practice. Cambridge University Press. DOI: https://doi.org/10.1017/CBO9781139226592

Nir, L. (2012). Cross-National Differences in Political Discussion: Can Political Systems Narrow Deliberation Gaps? Journal of Communication, 62(3), 553-570. DOI: https://doi.org/10.1111/j.1460-2466.2012.01648.x

Partheymüller, J., \& Schmitt-Beck, R. (2012). A "Social Logic" of Demobilization: The Influence of Political Discussants on Electoral Participation at the 2009 German Federal Election. Journal of Elections Public Opinion \& Parties, 22, 457-478. DOI: https://doi.org /10.1080/17457289.2012.720576

Pforr, K. (2014). Femlogit-Implementation of the multinomial logit model with fixed effects. Stata Journal, 14(4), 847-862. DOI: https://doi. org/10.1177/1536867X1401400409

Pincock, H. (2012). Does Deliberation Make Better Citizens? In Nabatchi, T., Gastil, J., Leighninger, M., \& Weiksner, G. M. (Eds.), Democracy in Motion: Evaluating the Practice and Impact of Deliberative Civic Engagement. Oxford University Press. DOI: https://doi. org/10.1093/acprof:oso/9780199899265.003.0007

Polletta, F., \& Gardner, B. (2018). The Forms of Deliberative Communication. In André Bächtiger, J., Dryzek, S., Mansbridge, J., \& Warren, M. (Eds.), The Oxford Handbook of Deliberative Democracy (pp. 70-85). Oxford University Press. DOI: https://doi. org/10.1093/oxfordhb/9780198747369.013.45

Prior, M. (2007). Post-Broadcast Democracy: How Media Choice Increases Inequality in Political Involvement and Polarizes Elections. Cambridge University Press. DOI: https://doi.org/10.1017/CBO9781139878425

Prior, M. (2019). Hooked: How Politics Captures People's Interest. Cambridge University Press. DOI: https://doi. org/10.1017/9781108355001

Reiljan, A. (2019). "Fear and loathing across party lines" (also) in Europe: Affective polarisation in European party systems. European Journal of Political Research, O(0). DOI: https://doi.org/10.1111/1475-6765.12351

Rinke, E. M., \& Moy, P. (2016, June 9). Political Information for Closed Minds: Effects of the Need for Cognitive
Closure on Political Interest and News Consumption. 66th Annual Conference of the International Communication Association, Fukuoka, Japan.

Roßteutscher, S., Schmitt-Beck, R., Schoen, H., Weßels, B., Wolf, C., Preißinger, M., Kratz, A., Wuttke, A., \& Gärtner, L. (2018). Short-term Campaign Panel (GLES 2017) (Version 6.0.0). GESIS Data Archive, Cologne. DOI: https://doi.org/10.4232/1.13150

Roßteutscher, S., Schmitt-Beck, R., Schoen, H., Weßels, B., Wolf, C., Wagner, A., Melcher, R., \& Giebler, H. (2019). Post-election Cross Section (GLES 2017) (Version 4.0.1). GESIS Datenarchiv, Köln. DOI: https://doi.org/10.5771/9783845287607-1

Schmitt-Beck, R., \& Lup, O. (2013). Seeking the Soul of Democracy: A Review of Recent Research into Citizens' Political Talk Culture. Swiss Political Science Review, 19(4), 513-538. DOI: https://doi.org/10.1111/ spsr.12051

Schoen, H., Rattinger, H., Preißinger, M., Gavras, K., \& Steinbrecher, M. (2017). Election Campaigns and Voter Decision-Making in a Multi-Party System. Nomos.

Steenbergen, M. R., Bächtiger, A., Spörndli, M., \& Steiner, J. (2003). Measuring Political Deliberation: A Discourse Quality Index. Comparative European Politics, 1(1), 21-48. DOI: https://doi.org/10.1057/ palgrave.cep.6110002

Sunstein, C. R. (2017). \#Republic: Divided Democracy in the Age of Social Media. Princeton University Press. DOI: https://doi.org/10.1515/9781400884711

Taber, C. S., \& Lodge, M. (2006). Motivated Skepticism in the Evaluation of Political Beliefs. American Journal of Political Science, 50(3), 755-769. DOI: https://doi. org/10.1111/j.1540-5907.2006.00214.x

Warren, M. E., \& Pearse, H. (Eds.). (2008). Designing Deliberative Democracy: The British Columbia Citizens' Assembly on Electoral Reform. Cambridge University Press. DOI: https://doi.org/10.1017/ CBO9780511491177

Wuttke, A. (2021). The Pleasure Principle: Why (Some) People Develop a Taste for Politics - Evidence from a pre-registered experiment. Politics and the Life Sciences, 40(1), 1-21. DOI: https://doi.org/10.1017/pls.2020.18

Wuttke, A., \& Schoen, H. (2019). Who were the voters behind theSchulzeffect? An analysis ofvoter trajectories in the run-up to the 2017 German federal election. In Korte, K.-R., \& Schoofs, J. (Eds.), Die Bundestagswahl 2017: Analysen der Wahl-, Parteien-, Kommunikationsund Regierungsforschung (pp. 47-62). Springer VS. DOI: https://doi.org/10.1007/978-3-658-25050-8_3 
How to cite this article: Gärtner, L., Wuttke, A., \& Schoen, H. (2021). Who Talks and Who Listens? How Political Involvement Influences the Potential for Democratic Deliberation in Everyday Political Talk. Journal of Deliberative Democracy, 17(2), pp. 13-30. DOI: https://doi.org/10.16997/jdd.983

\section{Submitted: 30 July 2019 Accepted: 02 June 2020 Published: 22 November 2021}

Copyright: () 2021 The Author(s). This is an open-access article distributed under the terms of the Creative Commons Attribution 4.0 International License (CC-BY 4.0), which permits unrestricted use, distribution, and reproduction in any medium, provided the original author and source are credited. See http://creativecommons.org/licenses/by/4.0/

Wournal of Deliberative Democracy is a peer-reviewed open access journal published by University of Westminster Press. 